\title{
Mathematical modelling and optimisation of a coulometric sensor-actuator system based on three-dimensional diffusion
}

\author{
Spas D. Kolev ${ }^{1}$ and Willem E. van der Linden \\ MESA Research Institute, Department of Chemical Technology, University of Twente, P.O. Box 217, 7500 AE Enschede (Netherlands) \\ Wouter Olthuis and Piet Bergveld \\ MESA Research Institute, Department of Electrical Engineering, University of Twente, P.O. Box 217, 7500 AE Enschede, (Netherlands)
}

(Received 16th September 1993)

\begin{abstract}
A mathematical model describing the processes taking place in a measuring cell with a coulometric sensor-actuator system was developed both for the cases of titration of strong and weak protolytes. It takes into consideration the three dimensional diffusion which ocurrs in the volume of the measuring cell. The boundary conditions express the fact that the walls of the measuring cell are impermeable to the chemical species participating in the protolytic interactions and that a constant current is applied at the actuator electrode. The model was numerically solved by the implicit alternating-direction finite-difference method. Experimental titrations of diluted solutions of nitric, acetic and butyric acid and potassium hydroxide with various concentrations were performed. The good agreement between the experimental results and the predictions of the model confirmed its validity and showed that the model can be used successfully for the quantitative description of real sensor-actuator systems. On the basis of model simulations, some important guidelines for manufacturing sensor-actuator systems with optimal design with respect to their performance (e.g., high sampling rates) were formulated. The conditions under which the general three-dimensional model can be reduced to a two dimensional one for speeding up the computations were determined. They cover most of the sensor-actuator systems currently used in practice. It was shown that the one-dimensional model, used until now, failed to describe quantitatively real sensor-actuator systems and can be applied only for deriving qualitative trends.
\end{abstract}

Keywords: Coulometry; Sensors; Diffusion equation; Mathematical modelling; Sensor-actuator system; Titration

Acid or base concentrations can be determined by performing an acid-base titration with coulometrically generated hydronium $\left(\mathrm{H}_{3} \mathrm{O}^{+}\right)$or hydroxyl $\left(\mathrm{OH}^{-}\right)$ions at an actuator electrode in

Correspondence to: W.E. van der Linden, MESA Research Institute, Department of Chemical Technology, University of Twente, P.O. Box 217, 7500 AE Enschede (Netherlands).

${ }^{1}$ Permanent address: Faculty of Chemistry, University of Sofia, 1 James Bourchier Ave., BG-1126 Sofia (Bulgaria). close proximity to a $\mathrm{pH}$ sensor. A schematic representation of the sensor-actuator device is given in Fig. 1. The titrant can be generated by the electrolysis of water at the actuator which usually is a noble metal electrode [1,2]:

$$
6 \mathrm{H}_{2} \mathrm{O} \Rightarrow 4 \mathrm{H}_{3} \mathrm{O}^{+}+4 \mathrm{e}^{-}+\mathrm{O}_{2}
$$

at the anode

$2 \mathrm{H}_{2} \mathrm{O}+2 \mathrm{e}^{-} \Rightarrow 2 \mathrm{OH}^{-}+\mathrm{H}_{2}$ at the cathode 
The $\mathrm{pH}$ sensor which is used as an indicator electrode monitors the changes in $\mathrm{pH}$ at its surface in time. A pH-sensitive ISFET can be successfully utilized [1-3]. The time dependence of the $\mathrm{pH}$ is similar to the dependence of the $\mathrm{pH}$ on the volume of the titrant added in classical titrations and for this reason is also referred to as titration curve.

The equivalence time, $t_{\text {eq }}$, which is determined as the inflection point of the titration curve, depends on the acid or base concentration of the sample solution.

Apart from the determination of acid or base concentrations, the coulometric sensor-actuator device has been used as the basic element of a carbon dioxide sensor [4] and has also been successfully applied as a pH-static enzyme sensor [5]. Recently, a modified version of this system has been shown to be able to determine the buffer capacity of a solution [6].

An early attempt to find an analytical expression between $t_{\mathrm{eq}}$ and the acid or base concentration was based on the statistics of the mean square distance that an ion travels in a given time interval and on the amount of generated titrant in that time interval [1]. A more sophisticated approach to describe the coulometric sensor-actuator system took the non-zero distance between the sensor and actuator into account [7]. The model was based on one-dimensional semi-infinite diffusive mass transport and was solved analytically giving an explicit relationship for cal- culating the equivalence time [7]. In addition to diffusive mass transfer, the effect of migration has been included and a one-dimensional diffusion-migration model has been developed, based on the solution of the Nernst-Planck equations [8].

The main advantage of the one-dimensional model is the relatively simple and little time-consuming numerical solution, and the possibility to derive some analytical expressions which can be used for a better understanding of the influence of some of the parameters on the behaviour of the system.

Their main drawbacks stem from the fact that in one dimension it is not possible to describe: (i) the complexity of the diffusion transport of all species participating in the chemical interactions; (ii) the influence of the geometrical dimensions of the actuator electrode and the sensor as well as the measuring cell. For these reasons the results obtained from these models had only a limited validity and required an extra fitting parameter in order to describe the multi-dimensional reality. For the adequate description and effective optimisation of sensor-actuator systems used in practice a general mathematical model overcoming these drawbacks is necessary. In the present paper the development of such a model and its experimental verification is reported. Some guidelines for optimising the design of sensor-actuator systems based on model simulation are also formulated.

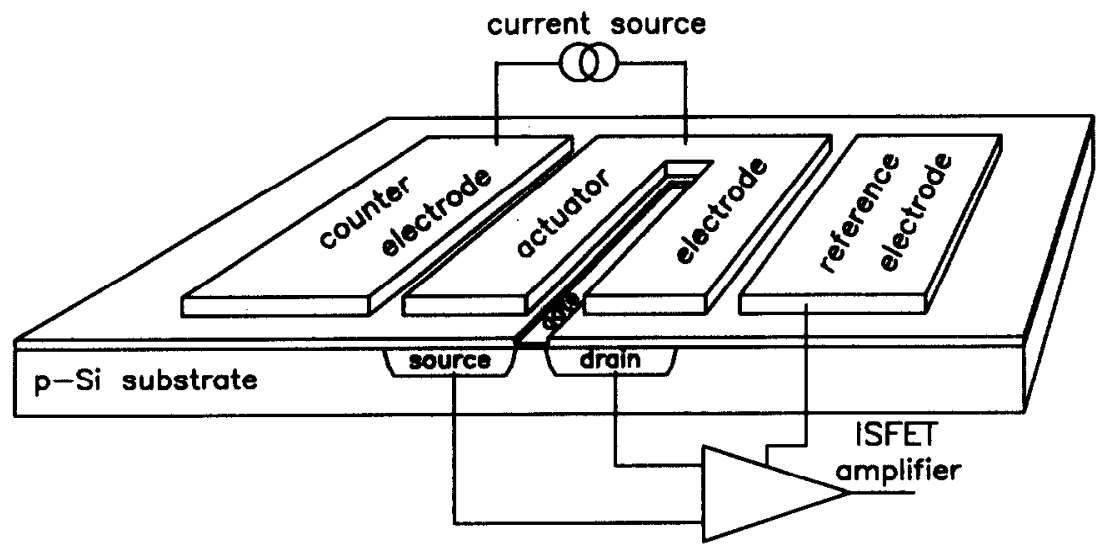

Fig. 1. The basic elements of an ISFET based sensor-actuator system. 


\section{DEVELOPMENT OF THE MATHEMATICAL MODEL}

The mathematical model proposed in the present study describes the sensor-actuator system schematically presented in Fig. 2 and is based on the following assumptions: (i) the mass transfer is the result only of Fickian diffusion, i.e., no migration or convective transport (resulting from either stirring or buoyancy) is taken into account; (ii) the walls of the vessel where the measurements are performed, i.e., the measuring cell, which are assumed to be rectangular, are impermeable to the interacting chemical species; (iii) the current at the actuator electrode is kept constant during measurements and no side reactions either at the actuator electrode or in the bulk of the solution take place; (iv) the protolytic interactions are assumed to be very fast so equilibrium is instantaneously established; (v) in the case of strong protolytes which are fully dissociated only the diffusion of the hydronium and the hydroxyl ions is taken into account while for weak protolytes the diffusion of all chemical species participating in the protolytic interaction is considered; (vi) the counter electrode is assumed to be far from the actuator electrode so that the chemical species generated there cannot influence the processes taking place at the sensor in the time interval during which measurements are performed; (vii) both the sensor and the actuator are assumed to lie at the same level as the bottom of the measuring cell; (viii) the signal measured is proportional
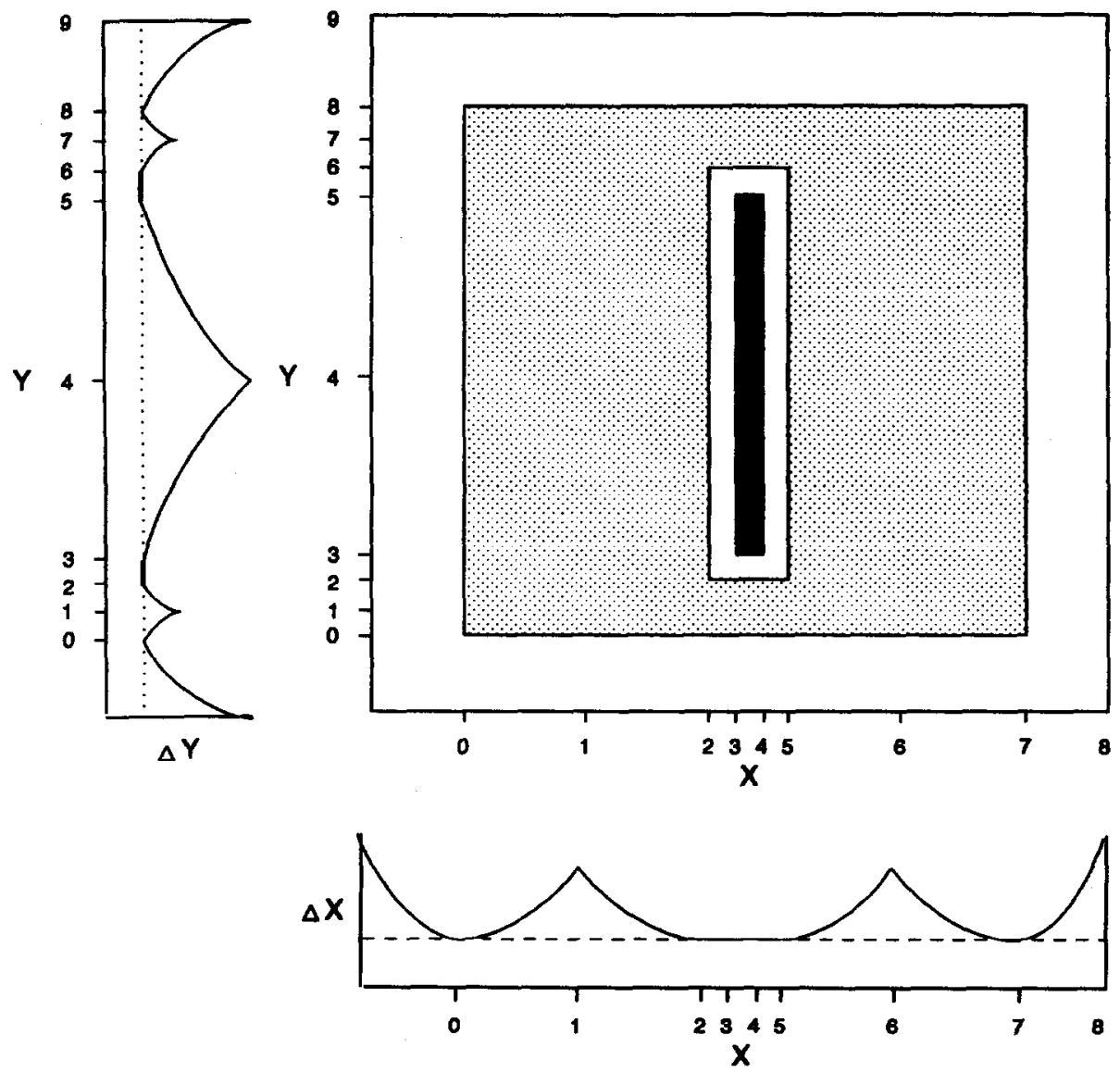

Fig. 2. Scheme of the bottom of the measuring cell and illustration of the way how the increments in $X$ and $Y$ direction vary. The dotted area refers to the actuator while the filled area refers to the sensor ( $\Delta X$ and $\Delta Y$ represent steps in the spatial grid). 
to the averaged pH over the sensor surface. Assumption (i) will hold in the presence of a sufficiently high concentration of supporting electrolyte [8]. Otherwise migration and probably buoyancy effects should be considered. With regard to assumption (ii), it can be said that in the case the walls of the measuring cell are situated far from the sensor-actuator ensemble, infinite diffusive mass transfer in $x$ and $y$ directions and semi-infinite diffusive mass transfer in $z$ direction will be encountered.

The chemical equilibrium which must be considered in the case of a strong protolyte is the dissociation of water. The symbols and their definitions are given in Table 1.

$\mathrm{H}_{2} \mathrm{O}+\mathrm{H}_{2} \mathrm{O} \rightleftharpoons \mathrm{H}_{3} \mathrm{O}^{+}+\mathrm{OH}^{-}$

with

$K_{\mathrm{W}}=c_{\mathrm{OH}^{-}} \boldsymbol{c}_{\mathrm{H}_{3} \mathrm{O}^{+}}$

The position of many solution equilibria depends on the electrolyte concentration of the medium. For this reason the concentration equilibrium constants (e.g., ion product of water, $K_{W}$, and the dissociation constants of acids and bases) must be corrected for the ionic strength, $\mu$, of the solutions.

$K_{\mathrm{W}}=K_{\mathrm{W}}^{\mathrm{t}} f_{\mathrm{H}_{3} \mathrm{O}^{+}}^{-1} f_{\mathrm{OH}^{-}}^{-1}$

where $K_{\mathrm{W}}$ is the concentration ion product of water, $K_{\mathrm{W}}^{\mathrm{t}}$ is the thermodynamic ion product of water and $f$ are the activity coefficients of the $\mathrm{H}_{3} \mathrm{O}^{+}$and $\mathrm{OH}^{-}$ions. They can be calculated according to the Debye-Hückel equation [9] (Appendix A).

In the case of a weak acid or a weak base besides Equilibrium 1 the corresponding dissociation process should be taken into account:

$\mathrm{H}_{2} \mathrm{O}+\mathrm{HA} \rightleftharpoons \mathrm{H}_{3} \mathrm{O}^{+}+\mathrm{A}^{-}$

with dissociation constant

$K_{\mathrm{a}}=c_{\mathrm{A}}-c_{\mathrm{HA}} / c_{\mathrm{HA}}$

$\mathrm{H}_{2} \mathrm{O}+\mathrm{B} \rightleftharpoons \mathrm{OH}^{-}+\mathrm{HB}^{+}$

with dissociation constant

$K_{\mathrm{b}}=c_{\mathrm{HB}}+c_{\mathrm{OH}^{-}} / c_{\mathrm{B}}$

where $K_{\mathrm{a}}=K_{\mathrm{a}}^{\mathrm{t}} f_{\mathrm{H}_{3} \mathrm{O}^{+}}^{-1} f_{\mathrm{A}^{-}}^{-1}$ and $K_{\mathrm{b}}=K_{\mathrm{b}}^{\mathrm{t}} f_{\mathrm{OH}^{-}}^{-1} f_{\mathrm{HB}^{+}}^{-1}$ (Appendix A).
TABLE 1

Symbols and definitions ${ }^{a}$

\begin{tabular}{|c|c|}
\hline$a$ & Coefficient defined in Eqns. 10e and 11e \\
\hline$b$ & Coefficient defined in Eqns. 10f, $11 \mathrm{f}$ and $12 \mathrm{e}$ \\
\hline$c$ & Concentration $\left(\mathrm{mol} \mathrm{m}^{-3}\right)$ \\
\hline$c_{0}$ & Initial concentration $\left(\mathrm{mol} \mathrm{m}^{-3}\right)$ \\
\hline C & $=c / c_{0}$. Dimensionless concentration \\
\hline$D_{\mathrm{m}}$ & Diffusion coefficient $\left(m^{2} s^{-1}\right)$ \\
\hline$D$ & $=D_{\mathrm{m}} / D_{\mathrm{mG}}$. Dimensionless diffusion coefficient \\
\hline$f$ & Activity coefficient \\
\hline$F$ & $=96486.332$. Faraday constant $\left(\mathrm{C} \mathrm{mol}^{-1}\right)$ \\
\hline$h$ & Exact value of the exponential coefficient \\
\hline$H$ & Approximate value of the exponential coefficient \\
\hline$j$ & Current density $\left(\mathrm{A} \mathrm{m}^{-2}\right)$ \\
\hline$J$ & $=-j L / \eta F D_{\mathrm{mG}} c_{0}$. Dimensionless current density \\
\hline$K_{w}^{t}$ & Thermodynamic ion-product of water $\left(\mathrm{mol}^{2} \mathrm{~m}^{-6}\right)$ \\
\hline $\boldsymbol{K}_{\mathbf{w}}$ & Concentration ion-product of water $\left(\mathrm{mol}^{2} \mathrm{~m}^{-6}\right)$ \\
\hline$K_{\mathrm{w}}^{\prime}$ & $=K_{w} /\left(c_{0}\right)^{2}$. Dimensionless ion-product of water \\
\hline$K^{\mathbf{w}}$ & Thermodynamic dissociation constant $\left(\mathrm{mol} \mathrm{m}^{-3}\right.$ ) \\
\hline$K$ & Concentration dissociation constant $\left(\mathrm{mol} \mathrm{m}^{-3}\right)$ \\
\hline$K^{\prime}$ & $=K / c_{0}$. Dimensionless dissociation constant \\
\hline$L$ & $=\max \left(X^{8}, Y^{9}\right\}$. Characteristic length $(\mathrm{m})$ \\
\hline$M$ & Degree of miniaturisation \\
\hline$n$ & Number of increments in a given direction \\
\hline$N$ & Total number of increments in a given direction \\
\hline$Q$ & $\begin{array}{l}\text { Approximate value of the spatial increment in a } \\
\text { given direction (m) }\end{array}$ \\
\hline$S$ & $\begin{array}{l}=Q / L \text {. Approximate dimensionless value of the } \\
\text { spatial increment in a given direction }\end{array}$ \\
\hline$s$ & $\begin{array}{l}\text { Exact dimensionless value of the spatial increment } \\
\text { in a given direction }\end{array}$ \\
\hline$t$ & Time (s) \\
\hline$x$, & $\begin{array}{l}\text { Directed distances in a Cartesian coordinate system } \\
\text { (m) }\end{array}$ \\
\hline$X, Y, Z$ & $\begin{array}{l}=x / L, y / L, z / L . \text { Dimensionless directed dis- } \\
\text { tances in a Cartesian coordinate system }\end{array}$ \\
\hline$\alpha, \beta$ & Coefficients defined in Table 2 \\
\hline$\Delta \Psi$ & $=\Delta X, \Delta Y, \Delta Z$. Dimensionless \\
\hline$\Delta \Psi$ & Coefficient defined in Table 2 \\
\hline$\eta$ & Charge of a given ion \\
\hline$\lambda$ & $\begin{array}{l}\text { Ratio between the square root of the equivalence } \\
\text { times calculated by the three and the two dimen- } \\
\text { sional model }\end{array}$ \\
\hline$\mu$ & Ionic strength \\
\hline$\theta$ & $=D_{\mathrm{mG}} t / L^{2}$. Dimensionless time \\
\hline$\rho$ & Effective diameter of a hydrated ion $(m)$ \\
\hline$\Psi$ & $\begin{array}{l}=X, Y, Z \text {. Dimensionless directed distances in a } \\
\text { Cartesian coordinate system }\end{array}$ \\
\hline
\end{tabular}

a Subscripts: $G$ refers to generated species; $T$ refers to titrated species, $\Psi$ refers to $X, Y$, or $Z$, eq refers to equivalence time, exp refers to experimental set-up, sim refers to data used in the simulations, subscripts $\mathrm{H}_{3} \mathrm{O}^{+}, \mathrm{OH}^{-}, \mathrm{HA}, \mathrm{A}^{-}, \mathrm{B}$, and $\mathrm{HB}^{+}$refer to $\mathrm{H}_{3} \mathrm{O}^{+}, \mathrm{OH}^{-}, \mathrm{HA}, \mathrm{A}^{-}, \mathrm{B}$, and $\mathrm{HB}^{+}$. Superscripts: $t$ refers to thermodynamic, $j$ refers to regions of the sensor-actuator system, and * refers to concentrations established after the chemical reaction step. 
The diffusion of the chemical species of interest $\left(\mathrm{H}_{3} \mathrm{O}^{+}\right.$and $\mathrm{OH}^{-}$in the case of a strong protolyte and $\mathrm{H}_{3} \mathrm{O}^{+}, \mathrm{OH}^{-}, \mathrm{HA}, \mathrm{A}^{-}, \mathrm{B}$, and $\mathrm{HB}^{+}$ in the case of a weak one) is described by Fick's second law in dimensionless quantities and variables.

$$
\begin{gathered}
\frac{\partial C_{\mathrm{G}}}{\partial \theta}=\frac{\partial^{2} C_{\mathrm{G}}}{\partial X^{2}}+\frac{\partial^{2} C_{\mathrm{G}}}{\partial Y_{2}}+\frac{\partial^{2} C_{\mathrm{G}}}{\partial Z^{2}} \\
\frac{1}{D_{\mathrm{i}}} \frac{\partial C_{\mathrm{i}}}{\partial \theta}=\frac{\partial^{2} C_{\mathrm{i}}}{\partial X^{2}}+\frac{\partial^{2} C_{\mathrm{i}}}{\partial Y^{2}}+\frac{\partial^{2} C_{\mathrm{i}}}{\partial Z^{2}}
\end{gathered}
$$

where subscript $\mathrm{G}$ refers to the generated species (i.e., $\mathrm{H}_{3} \mathrm{O}^{+}$or $\mathrm{OH}^{-}$) while subscript i refers to: $\mathrm{H}_{3} \mathrm{O}^{+}$in the case of a strong acid; $\mathrm{OH}^{-}$in the case of a strong base; $\mathrm{H}_{3} \mathrm{O}^{+}, \mathrm{HA}$, and $\mathrm{A}^{-}$in the case of a weak acid; and $\mathrm{OH}^{-}, \mathrm{B}$, and $\mathrm{HB}^{+}$in the case of a weak base.

In the case of a strong protolyte the diffusion of only two chemical species (the generated and the titrated species) should be considered, i.e., $\mathrm{H}_{3} \mathrm{O}^{+}$or $\mathrm{OH}^{-}$. Equations 7 and 8 allow to calculate their concentrations for a given time moment, i.e., $C_{\mathrm{G}}$ and $C_{\mathrm{T}}$. As a result of their chemical interactions their concentrations will be modified to $C_{\mathrm{G}}^{*}$ and $C_{\mathrm{T}}^{*}$. The resultant concentrations can be calculated by relationships derived on the basis of Eqn. 2.

$$
\begin{array}{lll}
C_{\mathrm{G}}^{*}=C_{\mathrm{G}}-G_{\mathrm{T}} & \text { if } & C_{\mathrm{G}}>C_{\mathrm{T}} \\
C_{\mathrm{G}}^{*}=K_{\mathrm{W}}^{\prime} /\left(C_{\mathrm{T}}-C_{\mathrm{G}}\right) & \text { if } & C_{\mathrm{G}}<C_{\mathrm{T}} \\
C_{\mathrm{G}}^{*}=\sqrt{K_{\mathrm{W}}^{\prime}} & \text { if } & C_{\mathrm{G}}=C_{\mathrm{T}} \\
C_{\mathrm{T}}^{*}=C_{\mathrm{T}}-G_{\mathrm{G}} & \text { if } & C_{\mathrm{T}}>C_{\mathrm{G}} \\
C_{\mathrm{T}}^{*}=K_{\mathrm{W}}^{\prime} /\left(C_{\mathrm{G}}-C_{\mathrm{T}}\right) & \text { if } & C_{\mathrm{T}}<C_{\mathrm{G}} \\
C_{\mathrm{T}}^{*}=\sqrt{K_{\mathrm{W}}^{\prime}} & \text { if } & C_{\mathrm{T}}=C_{\mathrm{G}}
\end{array}
$$

As an example of the titration of a weak protolyte the titration of a weak acid (HA) will be considered. Equations 7 and 8 allow to calculate for a given moment the following concentrations: $C_{\mathrm{H}_{3} \mathrm{O}^{+}}, C_{\mathrm{OH}^{-}}, C_{\mathrm{A}^{-}}$and $C_{\mathrm{HA}}$. As a result of the interactions between the hydronium and hydroxyl ions their concentrations will change. At the same time hydronium ions can be generated as a result of the dissociation of the weak acid $\mathrm{HA}$ leading to an additional change of $C_{\mathrm{OH}^{-}}$and $C_{\mathrm{H}_{3} \mathrm{O}^{+}}$. Obviously the concentrations of $\mathrm{HA}$ and $\mathrm{A}^{-}$will also change. The magnitude of this change, i.e., $b$ (Table 1), can be determined by substituting the concentrations after reaction $\left(C_{\mathrm{H}_{3} \mathrm{O}^{+}}^{*}, C_{\mathrm{A}^{-}}^{*}\right.$ and $C_{\mathrm{HA}}^{*}$, respectively) in Eqn. 4 and subsequently solving the resultant equation. Taking into consideration the dissociation of water (Eqn. 1) and the value of $a$ (Table 1), the actual values of the concentrations of $\mathrm{H}_{3} \mathrm{O}^{+}, \mathrm{OH}^{-}, \mathrm{HA}$ and $\mathrm{A}^{-}$in the time moment under consideration can be calculated. Depending on the concentrations of $\mathrm{H}_{3} \mathrm{O}^{+}, \mathrm{OH}^{-}$and $\mathrm{HA}$ obtained by Eqns. 7 and 8 the following cases with the corresponding relationships for $C_{\mathrm{OH}^{-}}^{*}, C_{\mathrm{H}_{3} \mathrm{O}^{+}}^{*}, C_{\mathrm{A}^{-}}^{*}$, and $C_{\mathrm{HA}}^{*}$ can be distinguished:

if $C_{\mathrm{OH}^{-}} \leq C_{\mathrm{H}_{3} \mathrm{O}^{+}}$:

$C_{\mathrm{H}_{3} \mathrm{O}^{+}}^{*}=a+b$

$C_{\mathrm{OH}^{-}}^{*}=K_{\mathrm{W}}^{\prime} /(a+b)$

$C_{\mathrm{A}^{-}}^{*}=C_{\mathrm{A}^{-}}+b$

$C_{\mathrm{HA}}^{*}=C_{\mathrm{HA}}-b$

where

$$
\begin{aligned}
& a=C_{\mathrm{H}_{3} \mathrm{O}^{+}}-C_{\mathrm{OH}^{-}} \\
& b=\left[-\left(a+C_{\mathrm{A}^{-}}+K_{\mathrm{a}}^{\prime}\right)\right. \\
& \left.+\sqrt{\left(a+C_{\mathrm{A}^{-}}+K_{\mathrm{a}}^{\prime}\right)^{2}-4\left(a C_{\mathrm{A}^{-}}-K_{\mathrm{a}}^{\prime} C_{\mathrm{HA}}\right)}\right] / 2
\end{aligned}
$$

if $C_{\mathrm{H}_{3} \mathrm{O}^{+}}<C_{\mathrm{OH}^{-}}<\left(C_{\mathrm{H}_{3} \mathrm{O}^{+}}+C_{\mathrm{HA}^{\prime}}\right)$

$$
\begin{aligned}
& C_{\mathrm{H}_{3} \mathrm{O}^{+}}^{*}=b \\
& C_{\mathrm{OH}^{-}}^{*}=K_{\mathrm{W}}^{\prime} / b \\
& C_{\mathrm{A}^{-}}^{*}=C_{\mathrm{A}^{-}}+a+b \\
& C_{\mathrm{HA}}^{*}=C_{\mathrm{HA}}-a-b
\end{aligned}
$$

where

$a=C_{\mathrm{OH}^{-}}-C_{\mathrm{H}_{3} \mathrm{O}^{+}}$

$b=\frac{-\left(a+C_{\mathrm{A}^{-}}+K_{\mathrm{a}}^{\prime}\right)+\sqrt{\left(a+C_{\mathrm{A}^{-}}+K_{\mathrm{a}}^{\prime}\right)^{2}-4 K_{\mathrm{a}}^{\prime}\left(a-C_{\mathrm{HA}}\right)}}{2}$

if $C_{\mathrm{OH}^{-}}=C_{\mathrm{H}_{3} \mathrm{O}^{+}}+C_{\mathrm{HA}}$ :

$C_{\mathrm{H}_{3} \mathrm{O}^{+}}^{*}=b$

$C_{\mathrm{OH}^{-}}^{*}=K_{\mathrm{W}}^{\prime} / b$ 


$$
\begin{aligned}
& C_{\mathrm{A}^{-}}^{*}=C_{\mathrm{A}^{-}}+C_{\mathrm{HA}} \\
& C_{\mathrm{HA}}^{*}=b\left(C_{\mathrm{A}^{-}}+C_{\mathrm{HA}}\right) / K_{\mathrm{a}}^{\prime} \\
& b=\sqrt{\frac{K_{\mathrm{a}}^{\prime} K_{\mathrm{W}}^{\prime}}{C_{\mathrm{A}^{-}}+C_{\mathrm{HA}}+K_{\mathrm{a}}^{\prime}}} \\
& \text { if } C_{\mathrm{OH}^{-}}>C_{\mathrm{H}_{3} \mathrm{O}^{+}}+C_{\mathrm{HA}^{\prime}}: \\
& C_{\mathrm{H}_{3} \mathrm{O}^{+}}^{*}=K_{\mathrm{W}^{\prime}} /\left(C_{\mathrm{OH}^{-}}-C_{\mathrm{HA}^{-}}-C_{\mathrm{H}_{3} \mathrm{O}^{+}}\right) \\
& C_{\mathrm{OH}^{-}}^{*}=C_{\mathrm{OH}^{-}}-C_{\mathrm{HA}^{-}}-C_{\mathrm{H}_{3} \mathrm{O}^{+}} \\
& C_{\mathrm{A}^{-}}^{*}=C_{\mathrm{A}^{-}}+C_{\mathrm{HA}} \\
& C_{\mathrm{HA}}^{*}=C_{\mathrm{H}_{3} \mathrm{O}^{+}}\left(C_{\mathrm{A}^{-}}+C_{\mathrm{HA}}\right) / K_{\mathrm{a}}^{\prime}
\end{aligned}
$$

The initial conditions of Eqns. 7 and 8 are: for $\theta=0$ :

$C_{\mathrm{G}}(X, Y, Z, 0)=0.0$

and

$C_{\mathrm{T}}(X, Y, Z, 0)=1.0$

For strong protolytes the titrated species are either $\mathrm{H}_{3} \mathrm{O}^{+}$or $\mathrm{OH}^{-}$with initial concentration equal to that of the corresponding fully dissociated acid or base $\left(C_{\mathrm{T}}\right)$. In the case of a weak acid the relationships for calculating the initial concentrations of chemical species of interest are the following [9]:

$$
\begin{aligned}
& C_{\mathrm{H}_{3} \mathrm{O}^{+}}^{*}=\frac{-K_{\mathrm{a}}^{\prime}+\sqrt{K_{\mathrm{a}}^{\prime 2}+4 K_{\mathrm{a}}^{\prime} C_{\mathrm{HA}}}}{2} \\
& \text { if } C_{\mathrm{HA}} \gg K_{\mathrm{a}}^{\prime}, C_{\mathrm{H}_{3} \mathrm{O}^{+}}^{*}=\sqrt{K_{a}^{\prime} C_{H A}} \\
& C_{\mathrm{OH}^{-}}^{*}=K_{\mathrm{W}^{\prime}}^{\prime} / C_{\mathrm{H}_{3} \mathrm{O}^{+}}^{*} \\
& C_{\mathrm{A}^{-}}^{*}=C_{\mathrm{H}_{3} \mathrm{O}^{+}}^{*}-C_{\mathrm{OH}^{-}}^{*} \\
& C_{\mathrm{HA}}^{*}=C_{\mathrm{HA}}+C_{\mathrm{A}^{-}}^{*}
\end{aligned}
$$

Similarly the relationships for calculating the initial concentrations of $\mathrm{H}_{3} \mathrm{O}^{+}, \mathrm{OH}^{-}, \mathrm{B}$ and $\mathrm{HB}^{+}$ for weak bases can be derived.

The boundary conditions of Eqns. 7 and 8 are the following:

$$
\begin{aligned}
& \left(\frac{\partial C(X, Y, Z, \theta)}{\partial \Psi}\right)_{\Psi=0, \Psi^{i}}=0 \\
& \left(\frac{\partial C(X, Y, Z, \theta)}{\partial Z}\right)_{Z=Z^{0}}=0
\end{aligned}
$$

where $\Psi$ and $j$ are $X$ and 8 , and $Y$ and 9 , respectively (Fig. 2).

At the bottom of the measuring cell, i.e., $Z=0$, the boundary condions are:

for the generated species (Eqn. 7):

$$
\begin{aligned}
& \left(\frac{\partial C_{\mathrm{G}}(X, Y, Z, \theta)}{\partial Z}\right)_{Z=0} \\
& \quad=\left\{\begin{array}{lll}
0 & \text { for } \quad X^{0}>X>X^{7} \text { or } Y^{0}>Y>Y^{8} \\
& \text { or } X^{5}>X>X^{2} \\
J \quad \text { for } & \begin{array}{l}
X^{7}>X>X^{0} \text { and } Y^{2}>Y>Y^{0} \\
\text { or } Y^{8}>Y>Y^{6}
\end{array}
\end{array}\right.
\end{aligned}
$$

for the chemical species whose diffusion is described by Eqn. 8:

$\left(\frac{\partial C(X, Y, Z, \theta)}{\partial Z}\right)_{Z=0}=0$

The signal monitored during the measurements, according to the assumptions on which the model is built, is proportional to the averaged $\mathbf{p H}$ over the area of the sensor.

$$
\mathrm{pH}(\theta)=-\int_{Y^{3}}^{Y^{5}} \int_{X^{3}}^{X^{4}} \log C_{\mathrm{H}_{3} \mathrm{O}^{+}}(X, Y, 0, \theta) \mathrm{d} X \mathrm{~d} Y
$$

For comparison the logarithm of the average concentration of the $\mathrm{H}_{3} \mathrm{O}^{+}$ions was also calculated.

$\log \overline{C_{\mathrm{H}_{3} \mathrm{O}^{+}}}(\theta)=\log \int_{Y^{3}}^{Y^{5}} \int_{X^{3}}^{X^{4}} C_{\mathrm{H}_{3} \mathrm{O}^{+}}(X, Y, 0, \theta) \mathrm{d} X \mathrm{~d} Y$

The time needed for reaching the equivalence point of the titration curve $[\mathrm{pH}(\theta)]$ was determined as the maximum of $\partial \mathrm{pH}(\theta) / \partial \theta$ which is actually its inflection point.

Though in the general case the model considers a three dimensional space it is possible to reduce the corresponding equations to two $(X, Z)$ and even to one $(X)$ dimensions. In the two-dimensional case all the partial derivatives with respect to $Y$ in the equations comprising the model are set to zero and $Y^{j}=0$ for $j=0-9$. In 
the one dimensional case besides setting the derivatives with respect to $Y$ and $Z$ to zero and $Y^{j}=0$ for $j=0-9$ and $Z^{0}=0$ and assuming that $X^{0}=X^{1}=X^{2}=0$ and $X^{5}=X^{6}=X^{7}=X^{8}=1$ (Fig. 2), some additional changes in the boundary conditions of Eqn. 7 should be made, i.e.,:

$$
\left(\frac{\partial C_{G}(X, \theta)}{\partial X}\right)_{X=0}=J
$$

and

$$
\left(\frac{\partial C_{G}(X, \theta)}{\partial X}\right)_{X=1}=-J
$$

\section{NUMERICAL SOLUTION OF THE MODEL}

The modification of Brian [10] of the implicit alternating-direction finite difference method (IADFDM) for two spatial variables [11] was selected for the numerical solution of Eqns. 7 and 8. The main advantages offered by this method are its unconditional stability and the possibility to apply the Gaussian elimination method for the solution of the sets of implicit equations in $X, Y$ and $Z$ directions because of their tridiagonal matrices. The IADFDM has been successfully applied to problems involving multidimensional diffusive and convective mass transport [12-14].

A mixed uniform/non-uniform space grid was used for reducing the computation time. The construction of this grid was oriented to the sensor-actuator geometry presented in Fig. 2. The highest density of nodes was located at the boundaries of the actuator and in its slit where the sensor (ISFET gate) was situated. In the areas far from these boundaries both within or outside the actuator surface the spatial increments $(\Delta \Psi)$ increased exponentially because there the variations in the concentration gradients are smaller and less grid points are necessary for an accurate representation.

$\Delta \Psi_{i}=s_{\Psi}^{j} \exp \left[h_{\Psi}^{j} i\right]$

where $s_{\Psi}^{j}$ is the basic increment and $h_{\Psi}^{j}$ is the exponential coefficient in the $j$ th region in direction $\Psi$ where $\Psi=X, Y, Z$. The regions with uniform and non-uniform exponentially increas- ing or decreasing spatial increments in $X$ and $Y$ directions are schematically presented in Fig. 2. In $Z$ direction the increments are monotonously increasing in an exponential way.

The algorithm for constructing the three dimensional space grid can be summarised in the following steps:

(1) Selection of the approximate values of the basic increments $S_{\Psi}$ (Eqn. 19) in all regions of a given direction $(\Psi=X, Y, Z)$ and the approximate values of the corresponding exponential coefficients $H_{\Psi}$.

(2) Calculation of the exact values of the basic increments and the exponential coefficients so that the boundaries of the walls of the measuring cell, the actuator and the sensor are coinciding with grid lines in the corresponding $X, Y$ or $Z$ direction. If this condition does not hold, the initial dimensions of the sensor actuator system will change when partial differential Eqns. 7 and 8 are decomposed into implicit finite-difference equations. In the regions with uniform space grid (Fig. 2) the exact values of the increments $\left(s_{\Psi}^{j}\right)$ and their number $\left(n_{\Psi_{i}}^{j}\right)$ can be determined by the following equations:

$n_{\Psi}^{j}=\left(\Psi^{j}-\Psi^{j-1}\right) / S_{\Psi}$

$s_{\Psi}^{j}=\left(\Psi^{j}-\Psi^{j-1}\right) / n_{\Psi}^{j}$

where for $\Psi=X, j=3,4,5$, and for $\Psi=Y$, $j=3,6$ (Fig. 2); $n_{\Psi_{i}}^{j}$ is the closest integer to the expression on the right hand-side of Eqn. 20;

In the regions with non-uniform space grid (for $\Psi=X, j=0,1,2,6,7,8$; for $\Psi=Y, j=0,1,2$, $4,5,7,8,9$; and for $\Psi=Z, j=0$ (Fig. 2)) it can be written:

$s_{\Psi}^{j}=S_{\Psi}$

$n_{\Psi}^{j}=\frac{1}{H_{\Psi}} \ln \left(1+H_{\Psi} \frac{\Psi^{j}-\Psi^{j-1}}{s_{\Psi}^{j}}\right)$

The derivation of Eqn. 23 is given in Appendix B. The exact value of the exponential coefficient $\left(h_{\Psi}^{j}\right)$ was determined as the root of the following equation:

$$
\frac{\Psi^{j}-\Psi^{j-1}}{s_{\Psi}^{j}}-\sum_{i=0}^{i=n_{\Psi}^{j}-1} \exp \left[h_{\Psi}^{j} I\right]=0
$$

where $I=i$ for exponentially increasing increments and $I=n_{\Psi}^{j}-i-1$ for exponentially de- 


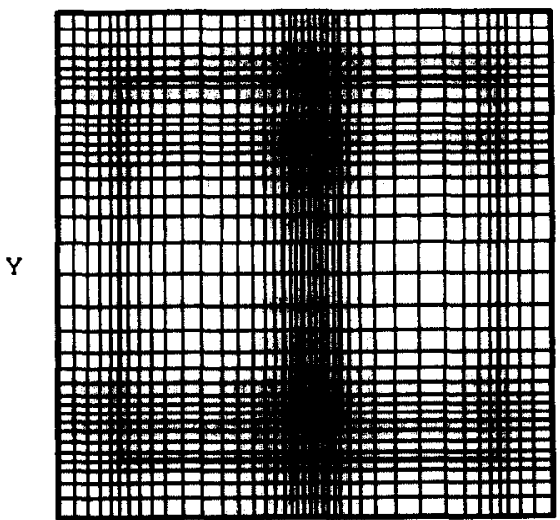

$x$
The formulas for finite-difference representation of the first and second derivatives necessary for decomposing the partial differential Eqns. 7 and 8 into the corresponding implicit finite-difference equations are given in Table 2 [14]. They were derived on the basis of Taylor's expansion [11].

An important step in developing the numerical procedure for the solution of the model is the integration of the $\mathrm{pH}$ and $C_{\mathrm{H}_{3} \mathrm{O}^{+}}$over the whole surface of the sensor. The main difficulty arises from the fact that during the period when the equivalence part of the titration curve is formed very large differences in the concentration of $\mathrm{H}_{3} \mathrm{O}^{+}$ions and the corresponding $\mathrm{pH}$ values evolve at the sensor surface which may lead to significant errors in the numerical integration. This effect is most profound in the direction of $X$ while it is not significant in the direction of $Y$. The magnitude of these errors can be reduced either by increasing the number of grid nodes in the direction of $X$ within the area of the sensor or by using formulas for numerical integration based on interpolating polynomials of higher degree (up to the 6th degree). The latter option seems to be more attractive because it does not lead to longer computation times. As far as the grid nodes in the direction of $X$ within the sensor area are equally spaced the Newton-Cotes formulas [11] are appropriate. The numerical integration in the direction of $Y$ was performed using the simple Trapezoidal rule.

The equivalence point of the titration curve was determined by its numerical differentiation. For improving the precision, the titration curve was approximated by an interpolating polynomial

TABLE 2

Finite-difference formulas for the partial derivatives in $X, Y$ and $Z$ in Eqns. 7 and 8 and their boundary conditions $16 a-16 e^{a}$

\begin{tabular}{lll}
\hline$\Psi$ & $X, Y$ & $Z$ \\
0 & $\partial C / \partial \Psi=0$ & $\partial C / \partial \Psi=J$ \\
& $\partial^{2} C / \partial \Psi^{2}=2\left(C_{1}-C_{0}\right) /\left(\Delta \Psi_{1}\right)^{2}$ & $\partial^{2} C / \partial \Psi^{2}=2\left(C_{1}-C_{0}\right) /\left(\Delta \Psi_{1}\right)^{2}-2 J / \Delta \Psi_{1}$ \\
$0<\Psi<\Psi^{j}$ & $\partial C / \partial \Psi=\left(C_{i}-C_{i-1}\right) / \Delta \Psi_{i}$ & $\partial C / \partial \Psi=\left(C_{i}-C_{i-1}\right) / \Delta \Psi_{i}$ \\
& $\partial^{2} C / \partial \Psi^{2}=\left(\alpha_{i} C_{i-1}-2 C_{i}+\beta_{i} C_{i+1}\right) / \Delta \Psi_{i}^{*}$ & $\partial^{2} C / \partial \Psi^{2}=\left(\alpha_{i} C_{i-1}-2 C_{i}+\beta_{i} C_{i+1}\right) / \Delta \Psi_{i}^{*}$ \\
$\Psi^{j}$ & $\partial C / \partial \Psi=0$ & $\partial C / \partial \Psi=0$ \\
& $\partial^{2} C / \partial \Psi^{2}=2\left(C_{N-1}-C_{N}\right) /\left(\Delta \Psi_{N}\right)^{2}$ & $\partial^{2} C / \partial \Psi^{2}=2\left(C_{N-1}-C_{N}\right) /\left(\Delta \Psi_{N}\right)^{2}$ \\
\hline a $N=\sum_{k=0}^{k=j} n_{\Psi}^{k} ; \alpha=2 \Delta \Psi_{i+1} /\left(\Delta \Psi_{i}+\Delta \Psi_{i+1}\right) ; \beta=2 \Delta \Psi_{i} /\left(\Delta \Psi_{i}+\Delta \Psi_{i+1}\right) ; \Delta \Psi_{i}^{*}=\Delta \Psi_{i} \Delta \Psi_{i+1} ;$ and $j=8$ for $\Psi=X, j=0$ for $\Psi=Y$, \\
$j=0$ for $\Psi=Z$.
\end{tabular}


of $n$th degree $(n=1-4)$ [11]. When the time increment was not small enough for reasons of speeding up the computations, slight fluctuations in the equivalence part of the titration curve were generated. In such cases the first derivative of the titration curve in its equivalence part appeared to be noisy and caused difficulties in determining the exact position of the inflection point. For eliminating this undesirable effect a smoothing procedure based on the Savitzky-Golay algorithm [15] prior to the numerical differentiation of the titration curve was applied.

In the case of a two dimensional space the implicit alternating-direction finite-difference method [11] was used while in the one dimensional case the classical implicit finite-difference method [11] was applied.

For speeding up the computations the sensor-actuator geometry was examined for the existence of symmetry in both $X$ and $Y$ directions. In the case of symmetry in one direction only half of the system was considered thus reducing the computation time by one half. In the case of symmetry in both $X$ and $Y$ directions only one fourth of the grid nodes were necessary for the calculations thus speeding up the computations by four times in comparison with the standard case of asymmetry in both $X$ and $Y$ directions.

The computer program calculating the titration curve, i.e., $\mathrm{pH}(\theta)$, and $\log C_{\mathrm{H}_{3} \mathrm{O}^{+}}$(Eqn. 17) was written in ANSIC and GNUCC and run on VAX/VMS or PC, respectively. The graphical representation of curves: $\mathrm{pH}(\theta), \overline{\mathrm{C}_{\mathrm{H}_{3} \mathrm{O}^{+}}}(\theta)$, and $\partial \mathrm{pH}(\theta) / \partial \theta$ and of the concentration distribution of the titrant and the titrated species as contour or three-dimensional plots was performed by another program written in Microsoft ${ }^{\$}$ Quick $C^{\left({ }^{\boxplus}\right.}$ Version 2.5 and run on a PC.

\section{EXPERIMENTAL}

\section{Preparation of the gold actuator-ISFET sensor device}

For the experiments described in this paper, a pH-sensitive ISFET was used as the sensing device. The ISFET was fabricated following the standard NMOS processing steps, with an added tantalum oxide gate dielectric on top of the silicon oxide [3]. The generation of ions was performed at a gold actuator electrode, deposited around the gate. This thin gold film $(0.6 \mu \mathrm{m})$ was evaporated on a $\mathrm{Ti} / \mathrm{Ag}$ adhesion promoting layer. The actuator electrode was patterned using standard photolithographic techniques. A layer of polyimide was spun on the wafer in which holes were etched both to contact the ISFET and the actuator electrode, and to free the area of the actuator electrode to be exposed to the solution. A cross-section of the device is shown in Fig. 4. After dicing the wafer, the chips were glued on a piece of printed circuit board of $1 \times 5 \mathrm{~cm}$ and connected to the available copper strips with bonding wires. The copper strips, the bonding wires and the edges of the chip were covered with epoxy for insulation and protection.

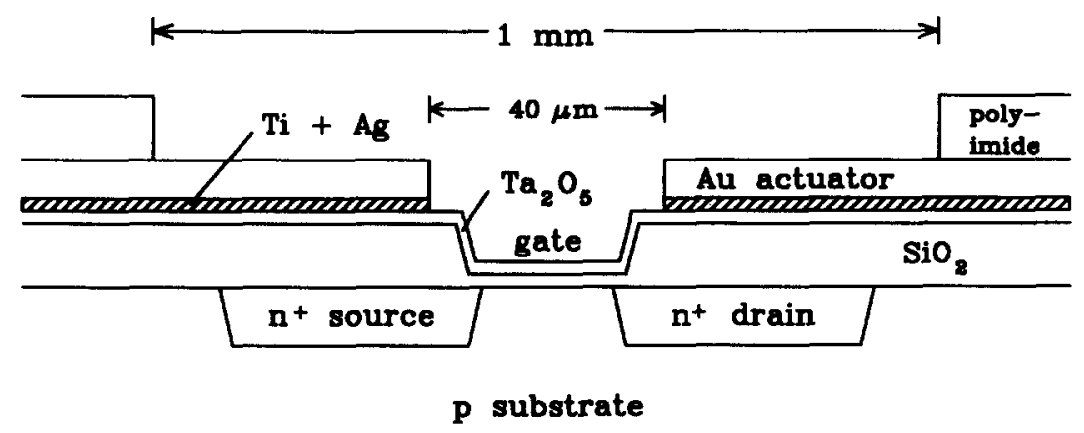

Fig. 4. Cross-section of the $\mathrm{Ta}_{2} \mathrm{O}_{5}-$ ISFET sensor with the gold actuator electrode. 


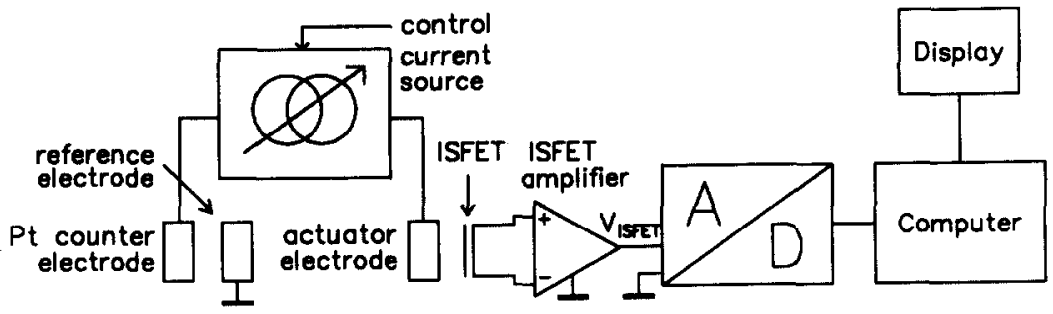

Fig. 5. Schematic representation of the measuring set-up.

\section{Measurement set-up}

All measurements have been carried out with the set-up as shown in Fig. 5. The ISFET amplifier keeps both the drain current and the drainsource voltage constant at $100 \mu \mathrm{A}$ and $0.5 \mathrm{~V}$, respectively. All coulometric titrations were carried out in a $0.1 \mathrm{M} \mathrm{KNO}_{3}$ supporting electrolyte at room temperature. The constant actuator electrode current was generated by a computer controlled current source. The time $t_{\text {eq }}$ was determined by the position of the extreme of the first derivative of the resulting titration curve.

\section{VERIFICATION OF THE MODEL}

The validity of the model was checked by experimental results for the titration of strong (nitric acid and potassium hydroxide) and weak (acetic acid and $n$-butyric acid) protolytes outlined earlier in the paper. The diffusion coefficients of the chemical species participating in the protolytic interactions and the corresponding dissociation constants are presented in Table 3 . The dimensions of the experimental sensor-actuator

TABLE 3

Diffusion coefficients, ion radii and dissociation constants $[9,16]$

\begin{tabular}{llrl}
\hline $\begin{array}{l}\text { Ions and } \\
\text { molecules }\end{array}$ & $\begin{array}{l}10^{9} \mathrm{D}_{\mathrm{m}} \\
\left(\mathrm{m}^{2} \mathrm{~s}^{-1}\right)\end{array}$ & $\rho(\AA)$ & $\begin{array}{l}10^{2} \mathrm{~K}_{\mathrm{a}}^{\mathrm{t}} \\
\left(\mathrm{mol} \mathrm{m}^{-3}\right)\end{array}$ \\
\hline $\mathrm{H}_{3} \mathrm{O}^{+}$ & 9.33 & 9 & \\
$\mathrm{OH}^{-}$ & 5.27 & 3.5 & \\
$\mathrm{CH}_{3} \mathrm{COO}^{-}$ & 1.09 & 4 & \\
$\mathrm{C}_{3} \mathrm{H}_{7} \mathrm{COO}^{-}$ & 0.868 & 4 & \\
$\mathrm{CH}_{3} \mathrm{COOH}$ & 1.21 & & 1.75 \\
$\mathrm{C}_{3} \mathrm{H}_{7} \mathrm{COOH}$ & 0.93 & & 1.54 \\
\hline
\end{tabular}

system used in the calculations are given in Table 4. The current density in all experiments was 20 $A \mathrm{~m}^{-2}$. During the experiments the sensor-actuator system operated in a measuring cell considerably exceeding the dimensions of the actuator electrode. To reduce the computation time the dimensions of the measuring cell were scaled down assuming that the sensor-actuator ensemble was $x^{0} \mu \mathrm{m}$ and $y^{0} \mu \mathrm{m}$ from the side walls and the solution layer above it was $z^{0} \mu \mathrm{m}$ thick (Figs. 2 and 3). In all the simulations it was assumed for simplicity that $x^{0}=y^{0}=z^{0}$ ranging from 300 to $2000 \mu \mathrm{m}$. For such dimensions of the measuring cell the processes taking place in the surrounding of the actuator did not affect the concentration of the titrated species at the boundaries of the measuring cell (Figs. 2 and 3), i.e., it was constant thus corresponding to the real situation during the experiments. The agreement between the experimental and the theoretically calculated values of the square root of the equivalence time is illustrated in Fig. 6. Real time $(t)$ is used instead of the dimensionless time $(\theta)$ in Fig. 6 and subsequent figures to improve clarity of

\section{TABLE 4}

Dimensions of the sensor-actuator system in $\mu \mathrm{m}$ (Fig. 1) (exp refers to the experimental set-up and sim refers to data used in the simulations)

\begin{tabular}{lllll}
\hline$j$ & $X_{\exp }^{j}-X_{\exp }^{j-1}$ & $Y_{\exp }^{j}-Y_{\exp }^{j-1}$ & $X_{\text {sim }}^{j}-X_{\text {sim }}^{j-1}$ & $Y_{\text {sim }}^{j}-Y_{\text {sim }}^{j-1}$ \\
\hline 1 & 240 & 112.5 & 200 & 200 \\
2 & 240 & 112.5 & 200 & 200 \\
3 & 12.5 & 25 & 10 & 10 \\
4 & 15 & 250 & 10 & 210 \\
5 & 12.5 & 250 & 10 & 210 \\
6 & 240 & 25 & 200 & 10 \\
7 & 240 & 112.5 & 200 & 200 \\
8 & & 112.5 & & 200 \\
\hline
\end{tabular}



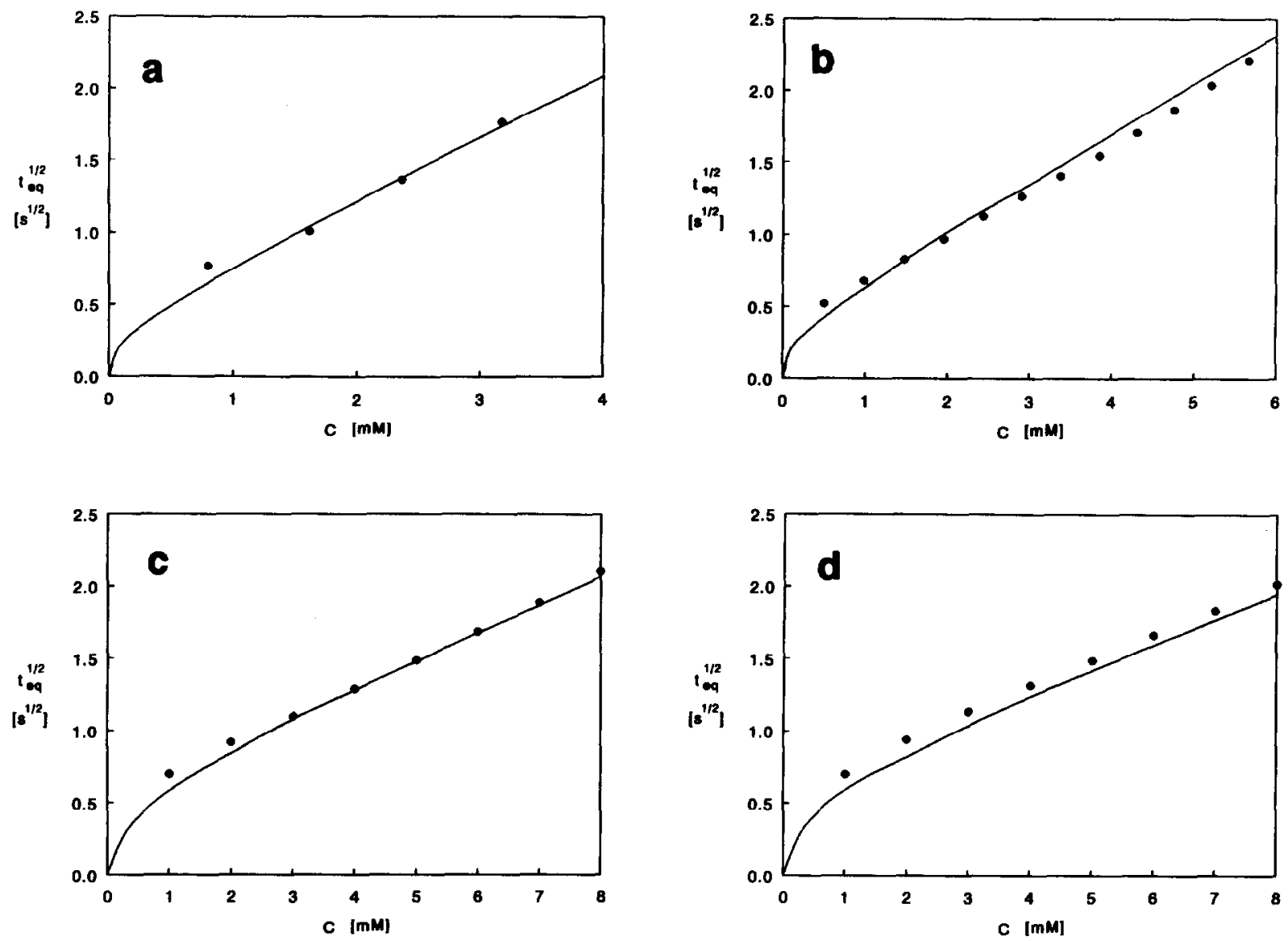

Fig. 6. Experimental ( $(\bullet)$ and theoretically calculated (bold line) values for the square root of the equivalence time versus concentration for: (a) nitric acid; (b) potassium hydroxide; (c) acetic acid; (d) $n$-butyric acid.

presentation. It should be emphasised that in the model simulations only fundamental physical constants with values taken from the literature and the real geometrical dimensions of the experimental sensor-actuator system were used. For this reason the good agreement between theory and experiments proved cogently the validity of the model.

\section{MODEL SIMULATIONS}

The mathematical model outlined above can be used not only for describing or predicting the titration curves monitored at a given coulometric sensor-actuator system but also for a better un- derstanding of the behaviour of the system. The latter can be achieved by elucidating the influence of the main parameters of the system under investigation on the titration curve and in particular on the equivalence time. The most important geometrical dimensions of the sensor-actuator system are the width of the actuator, the distance of the sensor from the actuator and the ratio between the length and the width of the sensor. Another important question concerning the manufacturing of sensor-actuator systems is how miniaturisation affects their behaviour and to what extent the symmetry of the sensor with respect to the slit influences the titration curve and the equivalence time. In the subsequent paragraphs these questions will be discussed on 


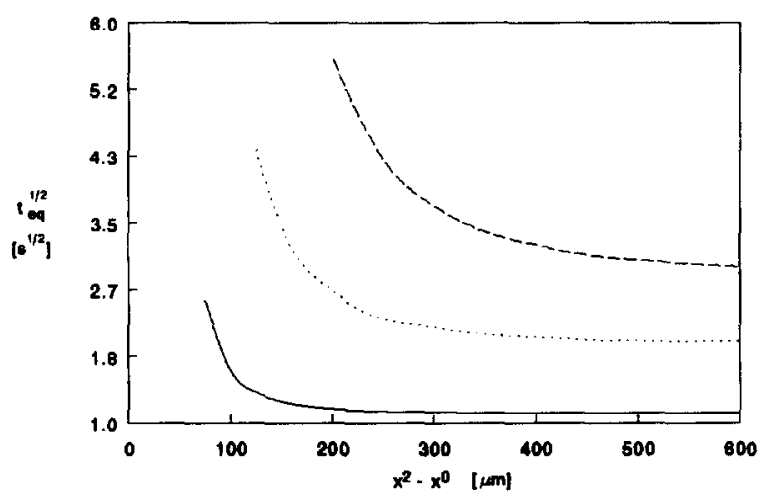

Fig. 7. Influence of the actuator width on the square root of the equivalence time in the case of titration of (—) 0.002 $\mathrm{M},(\cdots) 0.004 \mathrm{M}$, and (- - $0.006 \mathrm{M}$ strong acid.

the basis of results from model simulations. The dimensions of the sensor-actuator system, if not stated otherwise, were those presented in Table 4. The titration of a strong acid with values of the diffusion coefficients of the $\mathrm{OH}^{-}$and $\mathrm{H}_{3} \mathrm{O}^{+}$ions given in Table 3 and a concentration equal to $0.002 \mathrm{~mol} \mathrm{l}^{-1}$ was considered. The current density at the actuator was assumed to be $20 \mathrm{~A} \mathrm{~m}^{-2}$ throughout the simulations.

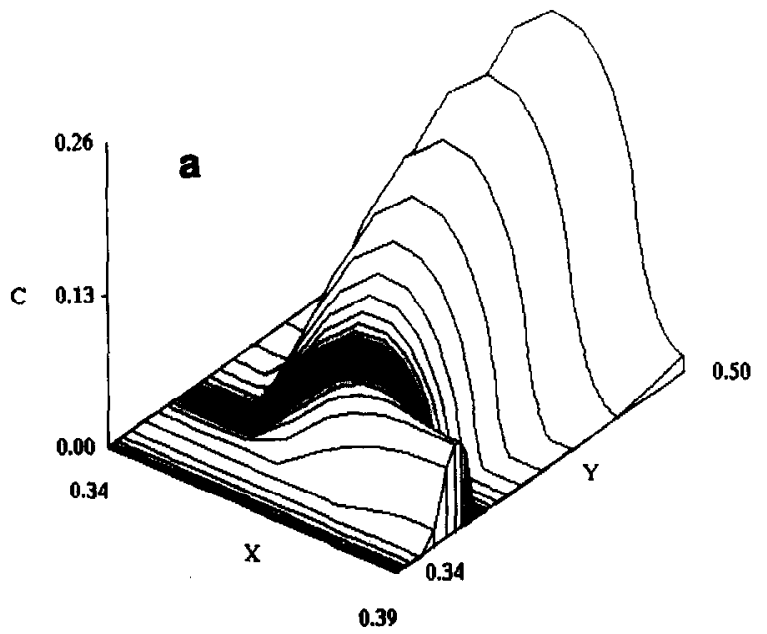

Width of the actuator

The width of the actuator is one of the main parameters of the system determining the equivalence time. During the simulations the width $\left(x^{2}-x^{0}=x^{7}-x^{5}=y^{2}-y^{0}=y^{8}-y^{6}\right.$, Fig. 2) was varied from 75 to $600 \mu \mathrm{m}$. As can be expected the wider the actuator is the shorter the equivalence time becomes reaching an asymptotic value (Fig. 7) which corresponds to infinite width. For small widths the equivalence time dramatically increases. This effect can be explained by the fact that for such sizes of the actuator conditions of spherical diffusion prevail before the equivalence time is reached. This phenomenon is illustrated in Fig. $8 \mathrm{a}$ by the spatial distribution of the titrant at the bottom of the measuring cell after the equivalence time has been reached. Only one fourth of the measuring cell is considered because of the symmetry in $x$ and $y$ directions. Under the conditions of spherical diffusion the expansion of the region around the actuator where the titrated species are practically depleted is much slower than before the establishment of the spherical diffusion regime. For wider actuator electrodes the equivalence time is much shorter because it is reached before the spherical diffu-

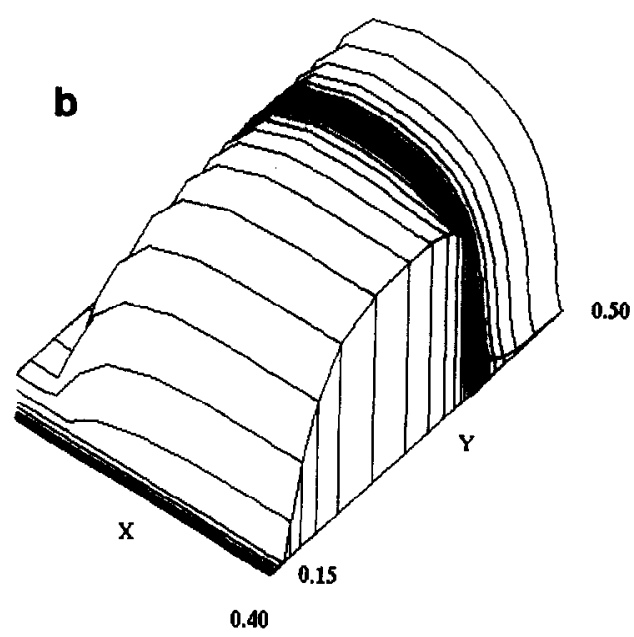

Fig. 8. Spatial distribution of the hydroxyl ions, right after the equivalence time for width of the actuator, (a) $75 \mu \mathrm{m}$ and (b) $500 \mu \mathrm{m}$ (titration of $0.002 \mathrm{M}$ strong acid). 

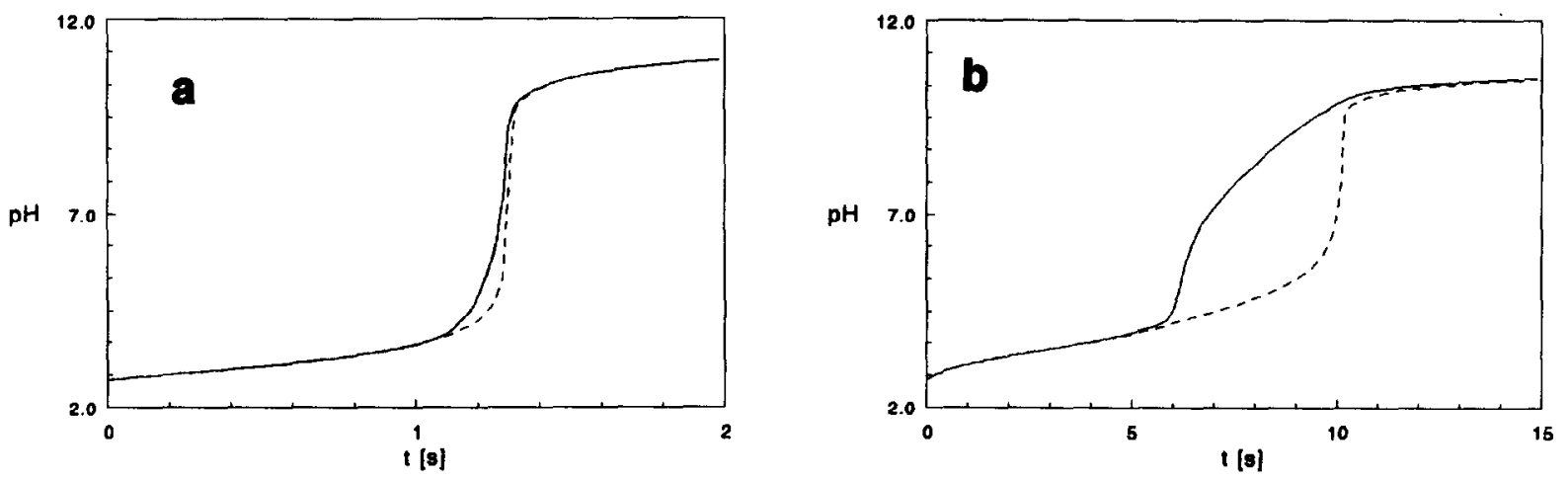

Fig. 9. Titration (- - and $\log \overline{\mathrm{C}_{\mathrm{H}_{3} \mathrm{O}^{+}}}(t)(\cdots)$ curves for width of the actuator, (a) $500 \mu \mathrm{m}$ and (b) $75 \mu \mathrm{m}$ (titration of $0.002 \mathrm{M}$ strong acid).

sion has been fully developed. In Fig. $8 \mathrm{~b}$ it can be seen that there are still traces of linear diffusion in the central part of the actuator after the equivalence time has been reached. The shapes of the titration curves obtained before and after the spherical diffusion has been established differ considerably. In the former case they are fairly symmetrical with respect to the inflection point and slightly differ from the negative logarithm of the averaged over the sensor surface concentration of the $\mathrm{H}_{3} \mathrm{O}^{+}$ions, i.e., $\log \overline{\mathrm{C}}_{\mathrm{H}_{3} \mathrm{O}^{+}}(t)$ (Fig. 9a). In the case of spherical diffusion, i.e., narrow actuator, the titration curves are not symmetrical and the difference between $\mathrm{pH}(t)$ and $\log$ $\overline{\mathrm{C}_{\mathrm{H}_{3} \mathrm{O}^{+}}}(t)$ is considerable (Fig. $\left.9 \mathrm{~b}\right)$. The equivalence part of $\mathrm{pH}(t)$ extends over a long period of time which may cause significant difficulties in the precise determination of the equivalence time. For higher concentrations of the titrated acid the critical width of the actuator below which the equivalence time grows very fast increases (Fig. 7). On the basis of the considerations made above it can be concluded that in constructing sensoractuator devices the actuator width should be selected in the asymptotic part of the dependence of the equivalence time on the actuator width (Fig. 7). Attention should be paid to the concentration range within which the measurements will be performed.

Distance between the actuator and the sensor

The distance between the sensor and the actuator $\left(x^{3}-x^{2}=x^{5}-x^{4}=y^{3}-y^{2}=y^{6}-y^{5}\right.$, Fig. 2) was varied from 0 to $20 \mu \mathrm{m}$. Within this range the equivalence time was reached before the establishment of spherical diffusion. An almost linear relationship between the equivalence time $\left(t_{\mathrm{eq}}\right)$ and the sensor-actuator distance $\left(x^{3}-x^{2}\right)$ was observed (Fig. 10).

Symmetry of the sensor with respect to the actuator slit

The positioning of the sensor in the centre of the actuator slit could pose some difficulties during the manufacturing of these devices. For this reason it is important to know what will be the impact of asymmetry on the equivalence time and the shape of the titration curves. Simulations

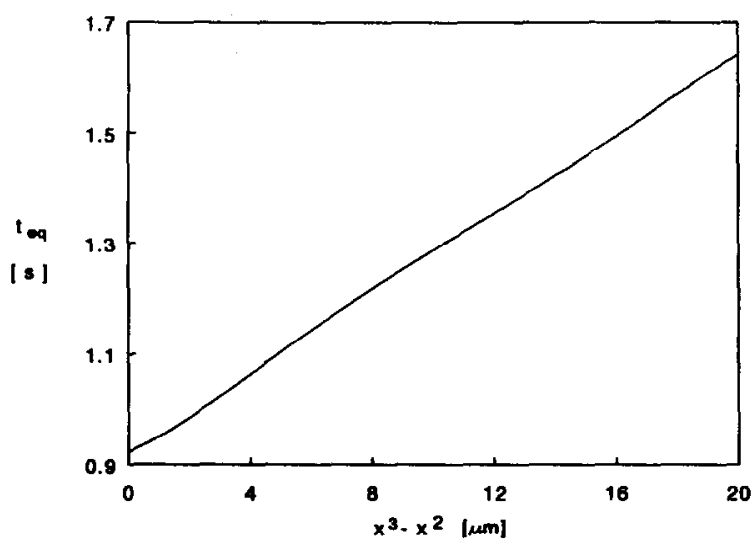

Fig. 10. Influence of the distance between the sensor and the actuator, i.e., $x^{3}-x^{2}=x^{5}-x^{4}=y^{3}-y^{2}=y^{6}-y^{5}$, on the equivalence time (titration of $0.002 \mathrm{M}$ strong acid). 


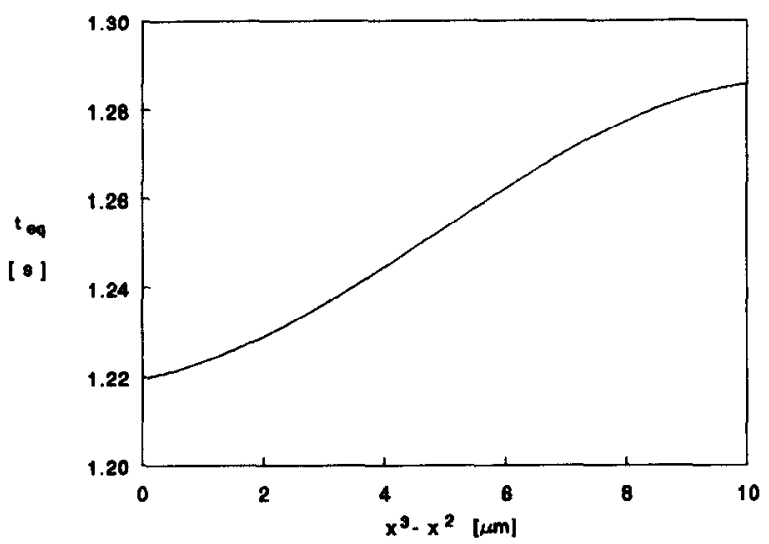

Fig. 11. Effect of asymmetry of the sensor with respect to the actuator $\left(x^{3}-x^{2}\right.$ is varied while $x^{5}-x^{2}$ is fixed at $30 \mu \mathrm{m}$ and $y^{3}-y^{2}$ and $y^{6}-y^{5}$ are kept equal to $10 \mu \mathrm{m}$ ) on the equivalence time (titration of $0.002 \mathrm{M}$ strong acid).

were performed assuming symmetry in the direction of $y\left(y^{3}-y^{2}=y^{6}-y^{5}\right.$, Fig. 2) and asymmetry in the direction of $x$. The distance $x^{3}-x^{2}$ was varied from 0 to $10 \mu \mathrm{m}$ keeping the slit length constant, i.e., $x^{5}-x^{2}=30 \mu \mathrm{m}$ (Fig. 2, Table 4). The dependence of the equivalence time on the distance $x^{3}-x^{2}$ is illustrated in Fig. 11. As can be seen the asymmetry slightly affects the equivalence time and in the extreme case when $x^{3}-x^{2}$ $=0 \mu \mathrm{m}$ and $x^{5}-x^{4}=20 \mu \mathrm{m}$ the equivalence time is decreased only by $5.4 \%$ with respect to the symmetrical case. In Fig. 12 titration curves calculated for different extent of asymmetry are presented. It can be seen that the greater the asymmetry is the lower the slope of the equivalence part the titration curve is (Fig. 12).

On the basis of the simulation results it can be concluded that if during manufacturing the sensor is placed slightly asymmetrically with respect to the actuator slit there will be no significant consequences on the behaviour of the system.

\section{Miniaturisation}

Miniaturisation of detectors is of vital importance for various fields of chemical analysis (e.g., chromatography, FIA, in vivo measurements, etc.). In this connection it is interesting to elucidate how miniaturisation of the sensor-actuator system considered in this study will affect its

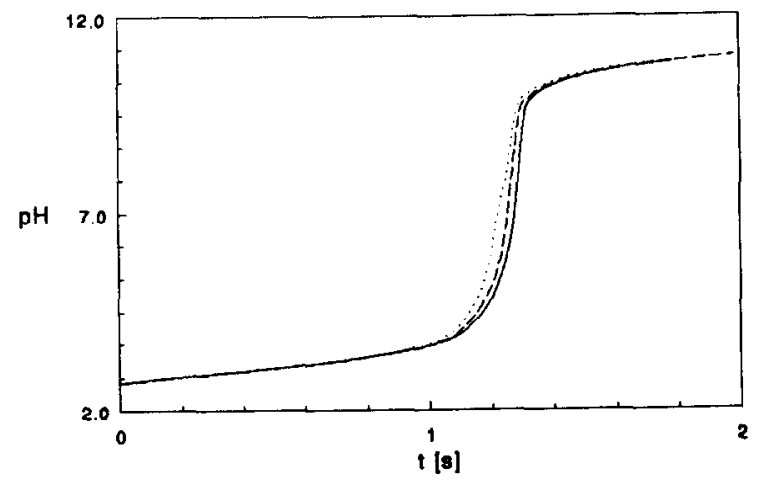

Fig. 12. Titration curves in the case of $(\cdots) x^{3}-x^{2}=0 \mu \mathrm{m}$ and $x^{5}-x^{4}=20 \mu \mathrm{m} ;(--\infty) x^{3}-x^{2}=4 \mu \mathrm{m}$ and $x^{5}-x^{4}$ $=16 \mu \mathrm{m}$; and $\left(\stackrel{2 \mathrm{~m}}{\longrightarrow} x^{3}-x^{2}=10 \mu \mathrm{m}\right.$ and $x^{5}-x^{4}=10$ $\mu \mathrm{m}$ (titration of $0.002 \mathrm{M}$ strong acid).

behaviour. In the subsequent considerations miniaturisation will be considered relative to the standard set of parameter values given in Table 4 . The degree of miniaturisation, $M$, is the linear scaling-up or -down factor. For the standard set it is equal to 1.0 . During the simulations $M$ was varied from 0 to 2 . Values of $M$ greater than 1 (i.e., scaling-up) were taken for comparison. Its influence on the equivalence time is presented in Fig. 13. The relationship between $M$ and $t_{\text {eq }}$ is linear for values of $M$ greater than 0.2 while for smaller values $t_{\text {eq }}$ rapidly decreases to 0 . In this region maximal gain in sampling frequency can be achieved. It should be taken into considera-

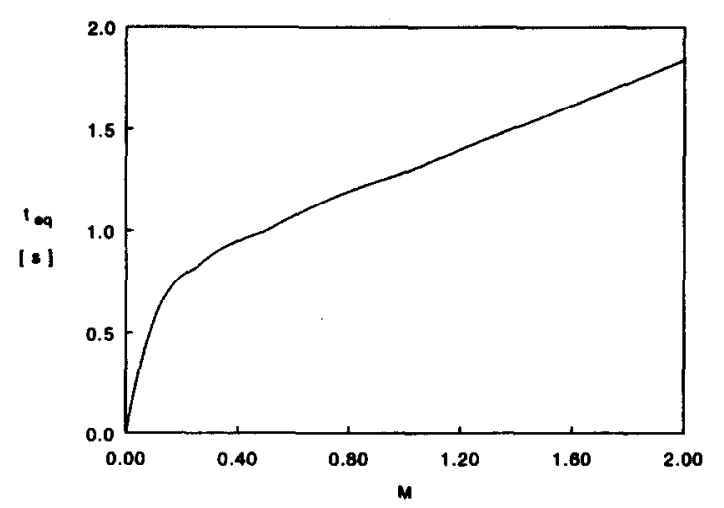

Fig. 13. Influence of miniaturisation on the equivalence time. (titration of $0.002 \mathrm{M}$ strong acid; $M$ is the degree of miniaturisation; $M=1$ is taken for standard set). 
tion that the influence of $M$ on $t_{\text {eq }}$ is also concentration dependent.

Possibilities for reducing the number of spatial coordinates

The substantial disadvantage of using three-dimensional models is the considerable consumption of computation time. The reduction of only one spatial variable in the model decreases dramatically the computation time from several hours to several minutes. In the one-dimensional case the computation time is in the order of seconds. Knowing under which conditions one can simplify the model without loosing precision, can speed up the computations by several orders of magnitude. Obviously, the most important parameter determining the possibility to neglect the diffusion in the direction of $y$ (Fig. 2) without creating substantial errors in the predictions is the widthto-length ratio of the slit of the actuator, $\left(y^{6}\right.$ $\left.y^{2}\right) /\left(x^{5}-x^{2}\right)$ (Fig. 2). For very large ratios the slit can be considered as infinitely long and diffusion in the direction of $y$ practically will not affect the processes taking place. Under such conditions the two dimensional model should describe adequately the titration curve, i.e., there should be no difference between the results obtained by the two- and three-dimensional models. When the width to length ratio is decreased diffusion in the direction of $y$ will start to affect the overall diffusion process thus decreasing the equivalence time in comparison with the infinite case. The discrepancy between the two- and three-dimensional models that will be observed can be represented as the ratio between the square root of the equivalence times calculated by the three and the two-dimensional models, $\lambda$. As could be expected, the simulations showed that $\lambda$ was equal to 1 for high width to length ratios and decreased when the ratio was reduced (Fig. 14a and b). Varying the sensor area, the strength and the concentration of the titrated protolyte showed that the width to length ratio of the slit almost solely determines the applicability of the two dimensional model. For values of this ratio greater than $\mathbf{1 0}$ the error in calculating the square root of the equivalence time is less than $1.5 \%$. By comparing the shape of the titration curves it can be

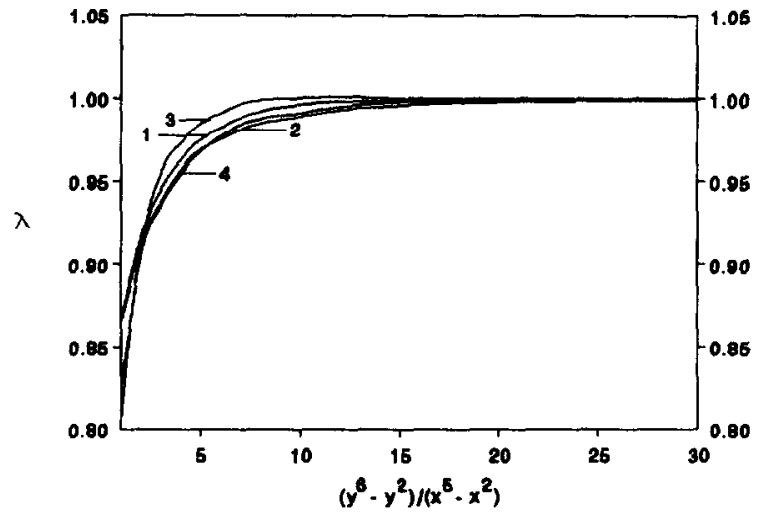

Fig. 14. Effect of the ratio between the width and length of the slit of the actuator on $\lambda$ in the case of: (1) $0.002 \mathrm{M}$ acetic acid, (2) $0.001 \mathrm{M}$ nitric acid, (3) $0.002 \mathrm{M}$ nitric acid, (4) 0.002 $M$ nitric acid when the area of the set of the slit.

said that for ratios not much greater than 10 the equivalence part of the titration curves calculated by the three-dimensional model is not so steep as in the case of the two dimensional model and the inflection point is slightly shifted to the upper region of the equivalence part of the titration curve (Fig. 15). By increasing $\lambda$ this difference decreases and the $\mathrm{pH}(t)$ and $\log \overline{\mathrm{C}_{\mathrm{H}_{3} \mathrm{O}^{+}}}(t)$ curves (Eqn. 17) almost totally overlap. Concerning the one dimensional case, it can be said that under no circumstances it can describe a real sensoractuator system. It cannot take into account the dimensions of the actuator and the diffusion and reaction above the bottom of the measuring cell.

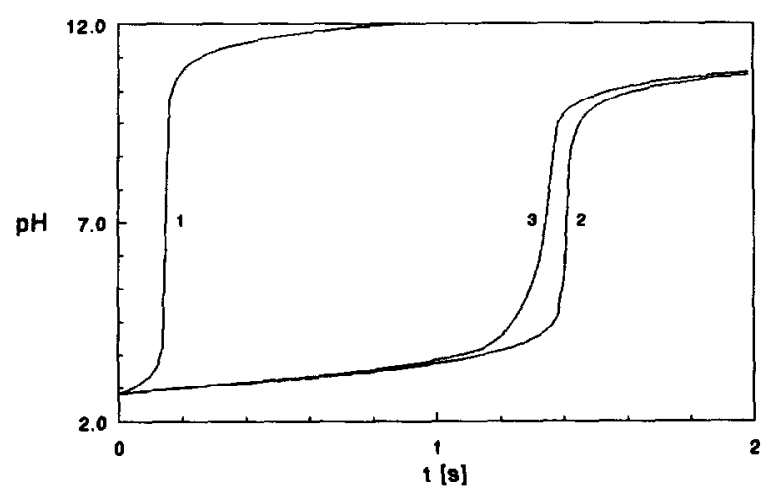

Fig. 15. Titration curves calculated by the (1) one; (2) twoand (3) three-dimensional model for $\lambda=10$. (titration of 0.002 M strong acid). 
For this reason the time interval necessary for the total depletion of the titrated protolyte in the slit was calculated to be much shorter than in reality. The equivalence time predicted by this model was by more than one order of magnitude lower than the one predicted by the threc-dimensional model. For this reason it can be concluded that the one-dimensional model can be used only for drawing qualitative conclusions concerning the parameters of the sensor-actuator system it takes into account, e.g., diffusion coefficients of the protolytes, current density, length of the slit and the sensor. When reliability is important or quantitative results are aimed at, the two or the three dimensional models should be preferred.

\section{Conclusions}

A general mathematical model describing the behaviour of a coulometric sensor-actuator system was developed. It takes into account the three-dimensional diffusion which takes place in real systems. The boundary conditions depict the impermeability of the walls of the measuring cell at the bottom of which the detector is placed and the constant current applied at the actuator electrode. These boundary conditions allow to take into consideration the influence of the depletion of the titrated species in the finite volume of the measuring cell on the titration curve monitored by the sensor. The very good agreement of the predictions of the model, when only basic physical constants are used, with experimental results is a convincing proof of its validity. It shows that the model can be used successfully for the quantitative description of the behaviour of real sensor-actuator systems. On the basis of model simulations, some important conclusions concerning the geometrical dimensions of sensor-actuator systems with optimal design can be drawn. In order to achieve small equivalence times, i.e., high sampling rates, the actuator should be wide enough to assure that the equivalence time is reached before spherical diffusion regime has been established. Another option for increasing the sampling throughput is the miniaturisation of the system. The simulations showed that not too much efforts should be put in placing the sensor absolutely symmetrically in the slit of the actuator because slight displacements from the symmetrical position will hardly affect the behaviour.

The conditions under which the two-dimensional model can be used for speeding up the computations were determined. They cover most the sensor-actuator systems used currently in practice.

This study has been carried out as part of an European Economic Community action for cooperation in science and technology with Central and Eastern European countries for 1993 and financed by the Commission of the European Communities. The authors are grateful to $\mathrm{Mr}$. E.H.J. Satink for carrying out most of the measurements.

\section{APPENDIX A}

For ionic strength of the solution not greater than 0.1 the activity coefficients of the various ions can be evaluated using the Debye-Hückel expression [9]:

$$
-\log f_{i}=\frac{0.509 \eta_{i}^{2} \sqrt{\mu}}{1+0.33 \rho \sqrt{\mu}}
$$

where $\mu=\frac{1}{2} \sum_{i} c_{i} \eta_{i}^{2}$ is the ionic strength of the solution and $\rho$ is the so-called ionic radius in $\AA$ [9] (Table 3).

\section{APPENDIX B}

\section{Derivation of Eqn. 23}

Let us consider the region stretching from $\Psi_{j-1}$ to $\Psi_{j}$ and assume that it is divided into $n_{\Psi}^{j}$ increments. Taking into consideration Eqn. 24 it can be written that:

$$
\Psi^{j}-\Psi^{j-1}=\int_{0}^{n_{\Psi}^{j}} s_{\Psi}^{j} \exp \left[H_{\Psi} i\right] \mathrm{d} i
$$

The integral on the right hand-side of Eqn. B1 can easily be solved analytically (Eqn. B2).

$$
\Psi^{j}-\Psi^{j-1}=\frac{s_{\Psi}^{j}}{H_{\Psi}}\left(\exp \left[H_{\Psi} n_{\Psi}^{j}\right]-1\right)
$$


Equation B2 can be rearranged with respect to $n_{\Psi}^{j}$ giving Eqn. 23.

\section{REFERENCES}

1 W. Olthuis, B.H. van der Schoot, F. Chavez and P. Bergveld, Sensors Actuators, 17 (1989) 279.

2 W. Olthuis, J. Luo, B.H. van der Schoot, J.G. Bomer and P. Bergveld, Sensors Actuators, B1 (1990) 416.

3 P. Bergveld and A. Sibbald, Analytical and Biomedical Applications of Ion-selective Field-effect Transistors, (Comprehensive Analytical Chemistry, Vol. XXIII), Elsevier, Amsterdam, 1988.

4 B.H. van der Schoot and P. Bergveld, Sensors Actuators, 13 (1988) 251.

5 B.H. van der Schoot and P. Bergveld, Anal. Chim. Acta, 233 (1990) 49.

6 J. Luo, W. Olthuis, P. Bergveld, M. Bos and W.E. van der Linden, Sensors Actuators, in press.
7 W. Olthuis, J. Luo, B.H. van der Schoot, P. Bergveld, M. Bos and W.E. van der Linden, Anal. Chim. Acta, 229 (1990) 71.

8 J. Luo, W. Olthuis, B.H. van der Schoot, P. Bergveld, M. Bos and W.E. van der Linden, Anal. Chim. Acta, 237 (1990) 71.

9 D.A. Skoog, D.M. West and F.J. Holler, Fundamentals of Analytical Chemistry, Saunders College Publishing, New York, 1988.

10 P.L.T. Brian, AIChE J., 7 (1961) 367.

11 B. Carnahan, H.A. Luther and J.O. Wilkes, Applied Numerical Methods, Wiley, New York, 1969.

12 S.D. Kolev and W.E. van der Linden, Anal. Chim. Acta, 257 (1992) 51.

13 S.D. Kolev and W.E. van der Linden, Anal. Chim. Acta, 257 (1992) 331.

14 S.D. Kolev, J.H.M. Simons and W.E. van der Linden, Anal. Chim. Acta, 273 (1993) 71.

15 A. Savitzky and M.J.E. Golay, Anal. Chem., 36 (1964) 1627.

16 D.R. Lide (Ed.), CRC Handbook of Chemistry and Physics, CRC Press, Boca Raton, FL, 1992. 